\title{
Sudden death of cardiac origin and psychotropic drugs
}

\section{Quadiri Timour ${ }^{1,2}$, Dominique Frassati ${ }^{3}$, Jacques Descotes ${ }^{2}$, Philippe Chevalier ${ }^{4,5}$, Georges Christé ${ }^{1}$ and Mohamed Chahine ${ }^{6}$}

${ }^{1}$ Laboratoire de Pharmacologie Médicale, EA 4612 Neurocardiologie: Physiopathologie des troubles du Rythme Cardiaque, Université Lyon 1, Lyon, France

${ }^{2}$ Centre Antipoison - Centre de Pharmacovigilance, Lyon, France

${ }^{3}$ Centre Hospitalier Spécialisé le Vinatier, Bron, France

${ }^{4}$ Unité de Rythmologie, Hopital Cardiologique, EA 4612 Neurocardiologie: Physiopathologie des troubles du Rythme Cardiaque, Lyon, France

${ }^{5}$ Centre de Référence des Troubles du Rythme d'origine Héréditaire, Lyon, France

${ }^{6}$ Institut Universitaire en Santé Mentale, Québec City, QC, Canada

\section{Edited by:}

Jean-François Desaphy, University of Bari Aldo Moro, Italy

Reviewed by:

Rudi Vennekens, Katholieke

Universiteit Leuven, Belgium

Akinori Kimura, Tokyo Medical and

Dental University, Japan

*Correspondence:

Quadiri Timour, Laboratoire de Pharmacologie Médicale, EA 4612

Neurocardiologie: Physiopathologie des Troubles du Rythme Cardiaque,

Université Lyon 1, F-69373 Lyon

CEDEX 8, France.

e-mail:quadiri.timour-chah@

univ-lyon 1.fr
Mortality rate is high in psychiatric patients versus general population. An important cause of this increased mortality is sudden cardiac death (SCD) as a major side-effect of psychotropic drugs. These SCDs generally result from arrhythmias occurring when the posology is high and may attain a toxic threshold but also at dosages within therapeutic range, in the presence of risk factors. There are three kinds of risk factors: physiological (e.g., low cardiac rate of sportsmen), physiopathological (e.g., hepatic insufficiency, hypothyroidism) and "therapeutic" (due to interactions between psychotropic drugs and other medicines). Association of pharmacological agents may increase the likelihood of SCDs either by (i) a pharmacokinetic mechanism (e.g., increased torsadogenic potential of a psychotropic drug when its destruction and/or elimination are compromised) or (ii) a pharmacodynamical mechanism (e.g., mutual potentiation of proarrhythmic properties of two drugs). In addition, some psychotropic drugs may induce sudden death in cases of pre-existing congenital cardiopathies such as (i) congenital long QT syndrome, predisposing to torsade de pointes that eventually cause syncope and sudden death. (ii) A Brugada syndrome, that may directly cause ventricular fibrillation due to reduced sodium current through Nav1.5 channels. Moreover, psychotropic drugs may be a direct cause of cardiac lesions also leading to SCD. This is the case, for example, of phenothiazines responsible for ischemic coronaropathies and of clozapine that is involved in the occurrence of myocarditis. The aims of this work are to delineate: (i) the risk of SCD related to the use of psychotropic drugs; (ii) mechanisms involved in the occurrence of such SCD; (iii) preventive actions of psychotropic drugs side effects, on the basis of the knowledge of patient-specific risk factors, documented from clinical history, ionic balance, and ECG investigation by the psychiatrist.

Keywords: sudden death, psychotropic drugs, cardiac arrhythmia, risk factor, side-effect

\section{INTRODUCTION}

The overall mortality rate in psychiatric patients is two- to fivefold higher than in the general population (Brown, 1997; Harris and Barraclough, 1998; Ruschena et al., 1998; Raedler, 2010) and their life expectancy is approximately $20 \%$ shorter (Newman and Bland, 1991). Mortality is higher in male than in female patients, especially when they are young (Hansen et al., 1997). This excess in mortality is partly linked to the use of psychotropic drugs, especially anti-depressants and neuroleptics (Frassati et al., 2004; Raviña et al., 2007b; Alvarez and Pahissa, 2010), but also amphetamines (Yim et al., 2008) and amphetamine-like derivatives, such as methylphenidate (Langendijk and Wilde, 2006) or lithium salts (Yap et al., 2009).

Death occurs more frequently in patients with extra-cardiac (hypokalemia, drug interactions) or cardiac risk factors (bradycardia, ischemia, dilated or hypertrophic cardiomyopathies, arrhythmogenic cardiopathies of the right ventricle, or other arrhythmias). Sudden death has indeed been reported in patients whose medical history included depolarization disorders, e.g.: reentry arrhythmia, such as Brugada syndrome. Right branch block with elevation of ST segment, a characteristic feature of Brugada syndrome, has been described during treatment with several psychotropic drugs (Rouleau et al., 2001). Thus, anti-depressants that selectively inhibit serotonin reuptake (SISR), such as fluvoxamine, or psychotropic drugs that decrease $\mathrm{Na}+$ entry via Nav1.5 channels (SCN5A) should not be prescribed to patients with abnormal Nav1.5 channels (Stirnimann et al., 2010) as this could worsen ECG alterations. Moreover, lithium salts induce ECG changes close to Brugada syndrome (Darbar et al., 2005). In addition, the medical history of patients with sudden death of cardiac origin includes repolarization disorders (e.g. prolonged QT interval). Indeed, a congenital or acquired long QT syndrome is an important cause of sudden death owing to pre-existing mutations of ion channels (in particular hERG channels), that predispose to fatal ventricular arrhythmias including torsades de pointe (TdP) potentially resulting in ventricular fibrillation (VF; Killeen, 2009). Voltage-clamp electrophysiological studies have shown that SISR, such as fluoxetine and norfluoxetine, one of its metabolites, selectively block 
hERG channels via two different mechanisms: (i) direct channel blockade, and (ii) disruption of channel protein trafficking (Rajamani et al., 2006). Recently, Lee et al. (2009) reported that sulpiride, a benzamide neuroleptic drug, can prolong the QT interval. These authors using the patch-camp technique on Purkinje fibers and mammalian cells transfected with hERG, KCNQ1/KCNE1, KCNJ2, and SCN5A cDNA, and rat myocytes overexpressing ICa showed that sulpiride increased the duration of action potentials owing to a significant reduction in IKr while its effects on INa, ICa, IKs, and IK1 currents were not significant. The prolongation of the QT interval by this neuroleptic drug is therefore linked to a blockade of hERG channels.

The results mentioned above clearly suggest that antidepressants and neuroleptics can affect several ion channels involved in the control of cardiac action potentials, and thus exert a proarrhythmic activity. A better understanding of genetics in this area can help clinicians to prevent life-threatening adverse events. A number of genes including SCN5A, SCN4B, CACNL1AC, KCNH2, KCNQ1, KCNE1, ANK2, ALG10, KCNJ2, KCNE2, RYR2, KCND3, KCND2, ACE, NOS1AP, CASQ2 and Rad have been associated with arrhythmias, and are good candidates to define a proarrhythmic genetic profile (Drago et al., 2008). Therefore, before prescribing anti-depressants and neuroleptics drugs, clinicians should be aware of known interactions of several genes (e.g. SCN5A, LQT1, LQT2, LQT3, LQT8) with these drugs in order to achieve a safer therapeutic use. Navedo et al. (2010) have shown the presence of a mutated calcium channel (Cav1.2) in Timothy syndrome that may induce arrhythmia and autism in humans (LQT8). However, to the best of our knowledge, no study showing interferences between psychotropic drugs and Cav1.2 has yet been published.

The objective of the present paper is to review the risk factors of sudden death of cardiac origin associated with the use of psychotropic drugs, the underlying mechanisms, and preventive measures.

\section{SUDDEN DEATHS OF CARDIAC ORIGIN ASSOCIATED WITH PSYCHOTROPIC DRUGS}

Sudden death of cardiac origin associated with the use of psychotropic drugs can occur in patients with pre-existing cardiopathies including ischemic, dilated, and hypertrophic cardiopathies. However, it is possible that psychotropic drugs can by themselves induce such pathological conditions.

\section{PSYCHOTROPIC DRUGS AND ISCHEMIC CARDIOPATHIES}

Several psychotropic drugs can induce thrombosis or coronary spasm, or even myocardial infarct (MI). Thorogood et al. (1992) observed a 17 -fold increase in the risk of fatal MI (relative risk: 16.9, 95\% confidence interval: 3.9-72.8) associated with the use of psychotropic drugs. Moreover, several studies highlighted the high incidence of ischemic cardiopathies correlated to the nature of the psychiatric disease. Thus, Jin et al. (2011) compared the risk of ischemic cardiopathy development in middle age and elderly psychotic patients with the general population over a 10 -year period. After excluding patients with a history of coronary disease or cerebral vascular accident, 179 patients were included. Of these, 68 had schizophrenia, 42 mood disorders, 38 insanity, and 31 severe depressions. Selected criteria for the analysis included previous medical and pharmacological treatments, physical examination, and the metabolic profile of patients. In order to assess the risk of developing ischemic cardiopathies according to the Framingham Heart Study (Levy et al., 1990), the authors calculated the risk of coronary disease in each patient, and then compared the relative risk associated with each psychiatric diagnosis. Compared to the general population, they found a $79 \%$ risk increase in patients with schizophrenia, $72 \%$ with depression, $61 \%$ with mood disorders related to psychosis, and $11 \%$ with dementia.

In addition, the analysis of the medical history and postmortem findings from 850 patients with schizophrenia who died from 1952 to 2007 found a tremendous increase in the incidence of pathological cardiac conditions, particularly chronic ischemic cardiopathy, MI and dilated cardiomyopathies. These findings may have been at least partly related to the long-term use of phenothiazine neuroleptics by schizophrenic patients (Volkov, 2009). It seems that the increased incidences of ischemic cardiopathies as well as the high morbidity and mortality rate in patients with schizophrenia are linked to treatments with atypical anti-psychotics. Indeed, such treatments are associated with metabolic disorders including weight gain, dyslipidemia, and deregulation of glucose metabolism, which have been suggested to increase the risk of coronary disease and diabetes in this population (Barnett et al., 2009).

A number of studies highlighted the existence of ischemic cardiopathies discovered at necropsy in patients previously treated with psychotropic drugs and who died of sudden cardiac death (Frassati et al., 2004). Recently, Suvisaari et al. (2010) studied the prevalence of coronary disease and MI in patients with psychotic disorders. They searched for anomalies of the cardiac conduction and the role of anti-psychotic drugs. The study was based on a representative national survey of 8,028 Finnish patients aged over 30 years. The diagnosis of coronary disease and MI was obtained from clinical and ECG findings. A number of ECG recordings evidenced large Q waves suggestive of a former MI. They were significantly more frequent in patients with schizophrenia than in patients without a medical history of psychiatric disorders. Overall, these results support the conclusion that ischemic cardiopathies are more frequent in patients with schizophrenia. One explanation could be at least in part that neuroleptic drugs could play a role by inducing metabolic disorders resulting in ischemic cardiopathies.

\section{PSYCHOTROPIC DRUGS AND CONGENITAL CARDIOPATHIES}

The incidence of sudden death associated with psychotropic drugs is very high in patients with various types of congenital cardiopathies.

The causative role of the amphetamine-like drug methylphenidate in sudden deaths occurring in teenagers have been highlighted by Langendijk and Wilde (2006) who reported 25 cases of sudden death defined according to the World Health Organization criteria following the use of methylphenidate and other amphetamine derivatives. The majority of victims were less than 18 years of age and the most fatal arrhythmias developed in teenagers with a congenital cardiopathy including the long QT congenital syndrome or a hypertrophic cardiomyopathy. 
Lithium salts that are widely used in the treatment of bipolar disorders are also associated with cardiac complications such as myocarditis (Talati et al., 2009), severe bradycardia (Waring, 2007), prolongation of the QT interval (van Noord et al., 2009), and severe ventricular arrhythmias potentially leading to VF and sudden death (Cruchaudet et al., 2002). Recently, a case of Brugada syndrome was reported in a 78-year-old patient with severe depression treated for 25 years with imipramine, amineptine, levomepromazine, and lorazepam. The addition of lithium salts induced a right branch block with elevation of the ST segment, reminiscent of a Brugada syndrome (Figure 1).

Accordingly, the use of psychotropic drugs that interfere with the fast $\mathrm{Na}^{+}$current and can cause reentry arrhythmias (Pacher and Kecskeméti, 2004) is contra-indicated in patients with Brugada syndrome (Antzelevitch et al., 2005; Table 1). Indeed, the density of $\mathrm{Na}^{+}$channels is reduced in these patients, which results in depressed membrane depolarization of ventricular cardiomyocytes (Brugada et al., 2005, 2009; Sicouri and Antzelevitch, 2008).

A majority of neuroleptics can prolong the QT interval and lead to TDP. This risk is particularly high in those patients with alterations of a structure or regulatory protein. Prolongation of the QT interval can be due to an improper inactivation of: (i) the $\mathrm{Na}$ channel Nav 1.5 (persisting $\mathrm{Na}^{+}$current through mutated SC5NA, responsible of LQT3) as is seen in the Romano-Ward syndrome characterized by prolonged QT interval and anomalies of T waves potentially leading to TDP; or (ii) the Ca channel Cav 1.2 (persisting Ca channel current responsible for LQT8) as is seen in the Timothy syndrome combining LQT8 and autism. A prolonged QT interval can also result from the loss of activity in the IKs (LQT1, LQT5) or IKr (LQT2, LQT6) channels, or from alterations of regulatory proteins, such as ankyrin B (LQT4) or caveolin 3 (LQT9) or the KvLQT1 protein (Romano Ward and Jervell syndrome). TDP have also been reported in patients treated with psychotropic drugs that block HERG (IKr) channels (acquired long QT syndrome: LQT1 and LQT2).

\section{MECHANISMS INVOLVED IN SUDDEN DEATHS OF CARDIAC ORIGIN}

Three main mechanisms can be involved in sudden deaths of cardiac origin: electrophysiological disturbances, myocardial ischemia, and myocarditis.

\section{SUDDEN DEATH DUE TO ELECTROPHYSIOLOGICAL DISTURBANCES}

The involved disturbances include either depolarization or repolarization disturbances.

Depolarization in ventricular cells depends on the fast $\mathrm{Na}^{+}$ inward current (Figure 2), the inhibition of which can induce reentry arrhythmias potentially resulting in VF. Disturbances of ventricular depolarization, which reflect delayed intra-ventricular depolarization, can be induced by many drugs that inhibit the entry of $\mathrm{Na}^{+}$ions in ventricular cardiomyocytes. These include neuroleptics (Lo Vecchio et al., 1996) and tricyclic anti-depressants (Leonard et al., 1995) when used alone or combined (Wilens et al., 1990). Moreover, tricyclic anti-depressants behave as class I antiarrhythmics, that is to say they can inhibit the fast $\mathrm{Na}^{+}$current (Mladosievicova et al., 1996). They can induce reentry arrhythmias (Figure 3) such as isolated or bursts of ventricular extra-systoles (VES), bigeminy, ventricular tachycardia (VT), ventricular flutters, or even VF and, in this case, sudden death.

Sudden deaths of cardiac origin can also be due to disturbances of repolarization. Psychotropic drugs that prolong the QT interval and can induce TDP include neuroleptics (Warner et al.,

Table 1 | Psychotropic drugs contra-indicated in patients with Brugada syndrome (Antzelevitch et al., 2005).

\begin{tabular}{ll} 
Therapeutic class & International \\
\hline Tricyclic anti-depressants & Clomipramine \\
Tetracyclic anti-depressants & Maprotiline \\
Inhibitors of serotonin reuptake & Fluoxetine \\
Phenothiazine neuroleptics & Cyamemazine
\end{tabular}

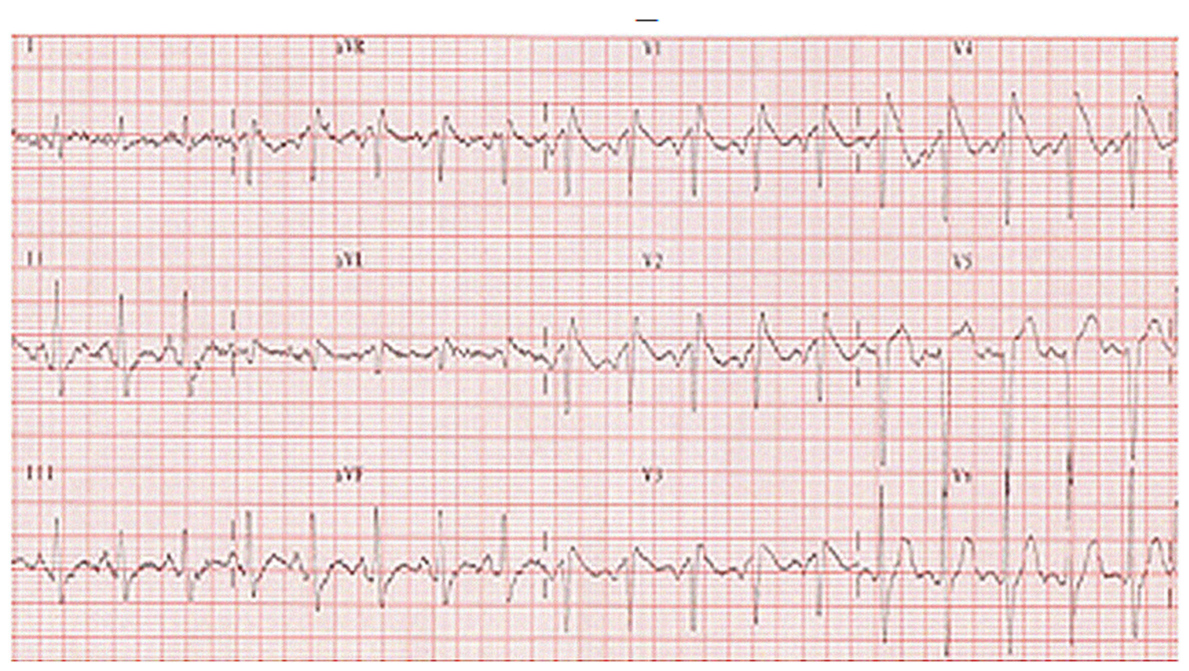

FIGURE 1 | Brugada syndrome. A=normal ECG; B= Brugada syndrome with right branch block and elevation of the ST segment. 

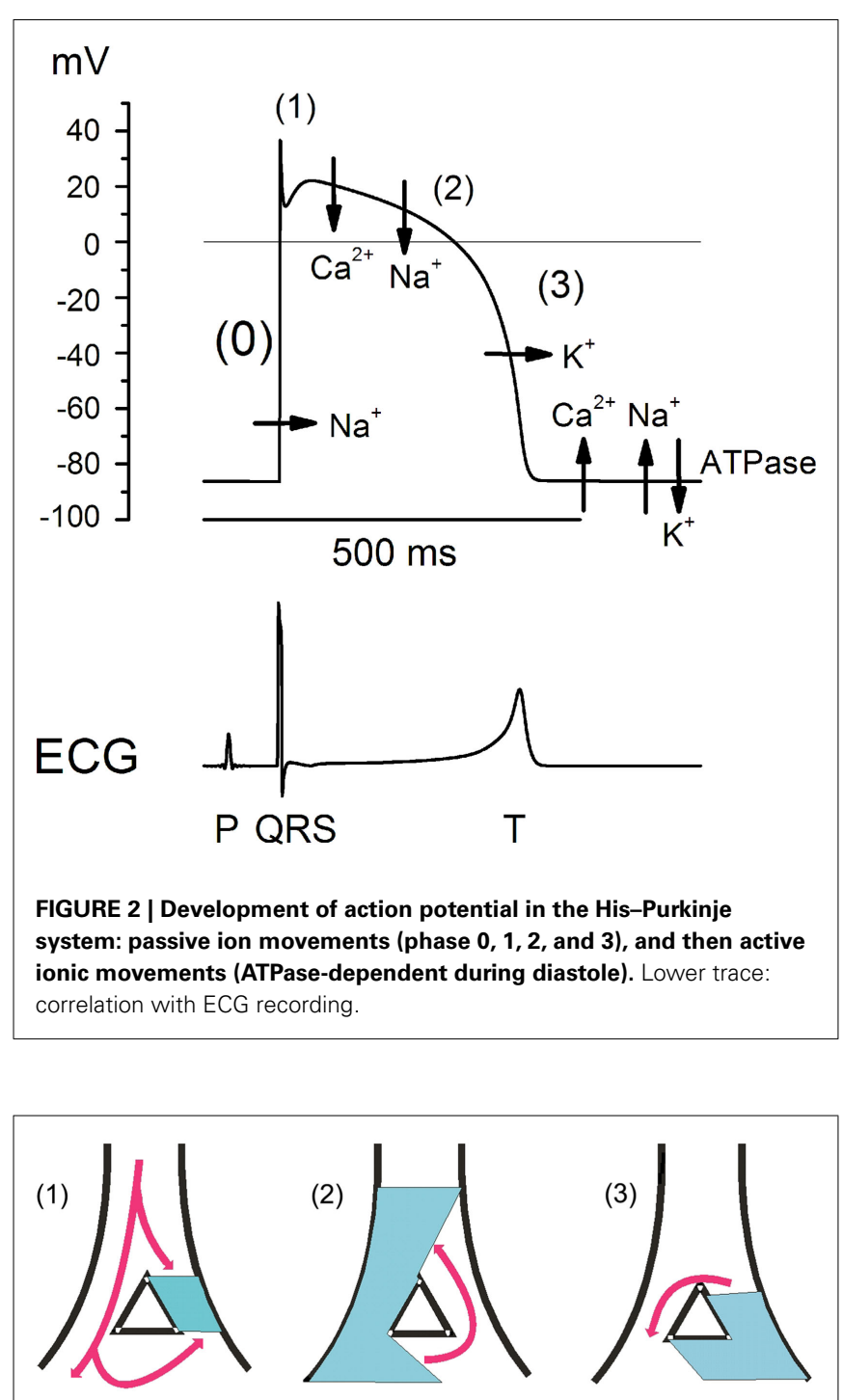

Zone in refractory period

FIGURE 3 | Reentry arrhythmias. They affect a restricted area (micro-reentry) or a large area (macro-reentry) of the myocardium. When the excitation wave goes down the intra-cardiac system that is blocked by an area in refractory period (A), it travels around and may excite it in a retrograde direction (the abnormal zone meanwhile comes out of its refractory period, see $(\mathbf{B})$. Then, the wave having reached the initial blockade point can, this time, travel in the normal direction (anterograde) to neighbor non-refractory fibers and cause a new premature contraction (C). This can originate an excitation wave rotating within a closed circle and that may propagate to adjacent myocardial tissues. NB: An identical phenomenon may occur in cases of myocardial ischemia, with a slowing down of intra-ventricular conduction in the ischemic area. The excitation wave reaches tissue that is no longer in refractory period and can travel in reverse direction, and thus, may cause reentry arrhythmias.

1996; Kitayama et al., 1999) and tricyclic anti-depressants (Rajamani et al., 2006). The most common causes include: (i) drugs such as antiarrhythmics, quinine, halofanthrine, neuroleptics, and tricyclic anti-depressants; (ii) ionic disturbances (hypokalemia); (iii) congenital anomalies (Jervell and Lange-Nielsen syndrome, Romano-Ward syndrome).

Among neuroleptics, old neuroleptics can be involved. Mehtonen et al. (1991) reported 49 cases of sudden death including 31 female and 18 male patients. Of these, 46 were treated with a therapeutic dose of a phenothiazine including thioridazine alone in 15 patients and combined with a tricyclic anti-depressant in 5 patients. The authors concluded that the cause of death was TDP resulting from prolonged QT interval. Recent neuroleptics can also be involved. Prolongation of the QT interval has been described with olanzapine (Olanzapine: New Preparation, 1999). Risperidone has also been incriminated in prolonged QTc ( $>450 \mathrm{~ms}$ ) followed by TDP. Raviña et al. (2007a) reported the death of an elderly woman treated with neuroleptics in which a ECG Holter recording has evidenced TDP that degenerated to VF. In addition, Pacher and Kecskemeti (2004) published prolongation of the QT interval in patients treated with atypical neuroleptics such as olanzapine, risperidone, sertindole, ziprasidone, quetiapine, and aripiprazole. The magnitude prolonged QT interval by aripiprazole has been highlighted by the US FDA in 2002 with $30-\mathrm{ms}$ prolongation in $3.7 \%$ of patients treated with $30 \mathrm{mg}$ /day versus $6 \mathrm{~ms}$ in patients under placebo. The magnitude of QTc prolongation is dose- and drug-dependent, which reflects the variable propensity of psychotropic drugs to interact with ion channels in the heart. Thoridazine and ziprasidone have been more often incriminated in QT prolongation and TDP, and this is due to the blockade of hERG channels, which facilitates early depolarizing post-potentials that may result in TDP (Figure 4) that can degenerate to VF in some instances. TDP can also be linked to the persistence of the $\mathrm{Na}^{+}$channel (LQT 3) or calcium channel (LQT8).

NB: The early after-depolarizations (EADs) are related to the activation of L-type calcium channels. These EADs are capable of inducing re-excitation and ventricular arrhythmias. The prolongation of this phase may, especially when it is heterogeneous, lead to torsades de pointes. This prolongation is either congenital (congenital long QT syndrome) or due to various drug intakes (acquired long QT syndrome, i.e., iatrogenic). Their occurrence is mainly favored by bradycardia and/or hypokalemia. Drugs potentially torsadogenic belong to many classes of drugs (see below).

\section{Tricyclic anti-depressants}

Curtis et al. (2003) retrospectively studied 4,825,345 patients aged over 18 years and identified 50 drugs with a high potential for inducing prolonged QT interval and 26 drugs that decrease the metabolic clearance of other drugs that prolong the QT interval. Among 1.1 million patients $(22.8 \%)$ treated with a drug prolonging the QT interval, $103,119(9.4 \%)$ were treated with 2 or more TDP-inducing drugs, or with a drug prolonging the QT interval combined with another drug inhibiting its hepatic metabolism. In addition, 7,249 $(0.7 \%)$ were treated with 3 or more drugs prolonging the QT interval. Overall, 22\% of patients were over 65 years of age and $74 \%$ were women. Anti-depressants were involved in nearly $50 \%$ of patients with prolonged QT interval. One recent finding is that anti-depressants, which specifically inhibit serotonin reuptake (ISRS), can prolong the QT interval (Rajamani 


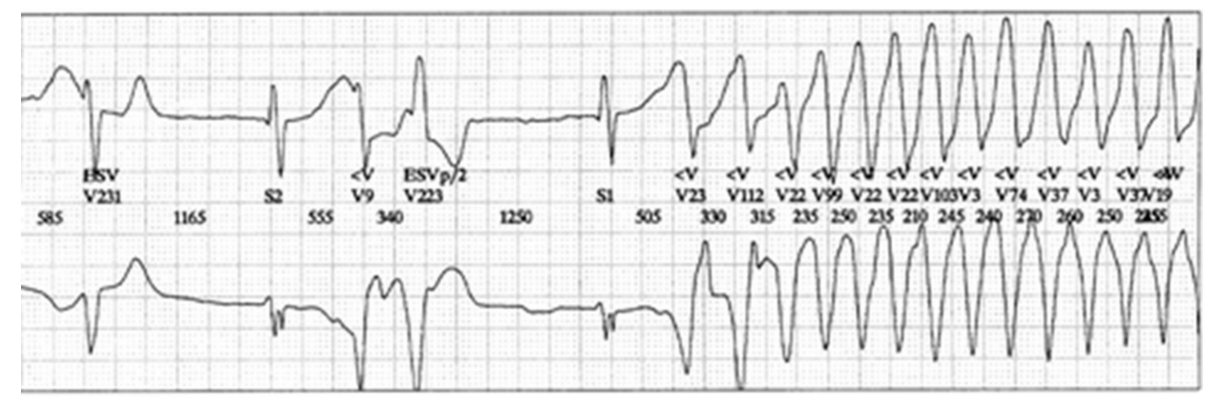

FIGURE 4 | Torsades de pointes.

Table 2 | Psychotropic drugs recognized by the Advisory Council of Arizona to have a real risk of torsades de pointes.

\begin{tabular}{|c|c|c|}
\hline $\begin{array}{l}\text { International } \\
\text { denomination }\end{array}$ & $\begin{array}{l}\text { Commercial } \\
\text { denomination }\end{array}$ & Therapeutic class \\
\hline Haloperidol & Haldol尺 & $\begin{array}{l}\text { Anti-psychotic/schizophrenia, } \\
\text { agitation }\end{array}$ \\
\hline Thioridazine & Mellaril $尺$ & Anti-psychotic/schizophrenia \\
\hline Mesoridazine & Serentil® & Anti-psychotic/schizophrenia \\
\hline Chlorpromazine & Thorazine $®$ & $\begin{array}{l}\text { Anti-psychotic/anti-emetic/ } \\
\text { schizophrenia/nausea }\end{array}$ \\
\hline
\end{tabular}

Table 3 | Psychotropic drugs implicated in the prolongation of the QT interval and in the genesis of torsades de pointes, but with a lack of sufficient evidence.

\begin{tabular}{|c|c|c|}
\hline $\begin{array}{l}\text { International } \\
\text { denomination }\end{array}$ & $\begin{array}{l}\text { Commercial } \\
\text { denomination }\end{array}$ & Therapeutic class \\
\hline Clozapine & Clozaril@ & Anti-psychotic/schizophrenia \\
\hline Escitalopram & Lexapro® & $\begin{array}{l}\text { Anti-depressant/major } \\
\text { depression/anxiety disorders }\end{array}$ \\
\hline Escitalopram & Cipralex® & $\begin{array}{l}\text { Anti-depressant/major } \\
\text { depression/anxiety disorders }\end{array}$ \\
\hline Paliperidone & Invega® & Anti-psychotic, atypical/schizophrenia \\
\hline Quetiapine & Seroquel尺 & Anti-psychotic/schizophrenia \\
\hline Risperidone & Risperdal@ & Anti-psychotic/schizophrenia \\
\hline Sertindole & Serdolect® & $\begin{array}{l}\text { Anti-psychotic, atypical/anxiety, } \\
\text { schizophrenia }\end{array}$ \\
\hline Sertindole & 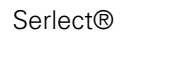 & $\begin{array}{l}\text { Anti-psychotic, atypical/anxiety, } \\
\text { schizophrenia }\end{array}$ \\
\hline Venlafaxine & Effexor® & Anti-depressant/depression \\
\hline Ziprasidone & Geodon® & Anti-psychotic/schizophrenia \\
\hline
\end{tabular}

et al., 2006). The role of ISRS is highlighted by prolongation of the QT interval in neonates whose mother has been treated with ISRS during pregnancy (Dubnov et al., 2005).

The Arizona Center for Education and Research on Therapeutics (The Critical Path Institute, Tucson, Arizona, and Rockville, MD, USA) proposed a classification based on the potential for psychotropic drugs to prolong the QT interval and induce TDP (Tables 2-4).
Table 4 | Psychotropic drugs, which in some studies, were weakly associated with QT interval prolongation and/or torsades de pointes.

\begin{tabular}{|c|c|c|}
\hline $\begin{array}{l}\text { International } \\
\text { denomination }\end{array}$ & $\begin{array}{l}\text { Commercial } \\
\text { denomination }\end{array}$ & Therapeutic class \\
\hline Amitriptyline & Elavil@ & Tricyclic anti-depressant/depression \\
\hline Citalopram & Celexa® & Anti-depressant/depression \\
\hline Clomipramine & Anafranil ( & Tricyclic anti-depressant/depression \\
\hline Desipramine & Pertofrane $\AA$ & Tricyclic anti-depressant \\
\hline Doxepin & Sinequan $®$ & Tricyclic anti-depressant/depression \\
\hline Fluoxetine & Sarafem $®$ & Anti-depressant/depression \\
\hline Fluoxetine & Prozac $®$ & Anti-depressant/depression \\
\hline Imipramine & Norfranil@ & Tricyclic anti-depressant/depression \\
\hline Nortriptyline & Pamelor® & Tricyclic anti-depressant/depression \\
\hline Paroxetine & Paxil@ & Anti-depressant/depression \\
\hline Protriptyline & Vivactil $\circledast$ & Tricyclic anti-depressant/depression \\
\hline Sertraline & Zoloft $\circledast$ & Anti-depressant/depression \\
\hline Trazodone & Desyrel $\circledast$ & Anti-depressant/depression, insomnia \\
\hline Trimipramine & Surmontil@ & Tricyclic anti-depressant/depression \\
\hline
\end{tabular}

However, the risk of torsades de pointes is low when used at recommended doses and/or in patients without risk factors (e.g., bradycardia, electrolyte disturbances and congenital long QT syndrome, in association with inhibitors of CYP 450 responsible for the metabolism of psychotropic drugs concerned). NB. Classification of Arizona does not include all psychotropic drugs that may prolong the QT interval and cause torsades de pointes. This is the case, for example, of pimozide. It is necessary therefore to be especially careful and evaluate the risk for non-listed drugs. NB. Actions to be taken when prescribing neuroleptics and anti-depressants to patients with disorders of repolarization and/or treated by antiarrhythmic drugs or other potentially torsadogenic drugs: Use a neuroleptic or an anti-depressant at low torsadogenic potential. Make sure the ion balance, particularly in serum potassium. Discard, if possible, the use of drugs that induce bradycardia. Perform an ECG and an ionic balance before the introduction of torsadogenic psychotropics (Lin et al., 2004; Narang et al., 2010). A cardiology consultation may sometimes be necessary.

\section{SUDDEN DEATHS DUE TO MYOCARDITIS AND MYOCARDIOPATHIES}

Another mechanism of sudden death associated with the use of neuroleptics is the development of myocarditis. One of the first studies to report on the responsibility of neuroleptics in the generation of myocarditis and myocardiopathy was that of Kilian et al. (1999) on clozapine. This Australian study included 8,000 patients from 1993 to 1999 and described structural lesions in 23 patients 
(20 men and 3 women, mean age: $36 \pm 9$ years). Among these 23 patients, 5 had cardiomyopathy of which one died after 36 months of treatment. The 18 remaining patients had myocarditis and 5 died ( 3 of sudden death and 2 of cardiac insufficiency) within the 3 first weeks of treatment. In addition, the risk of myocarditis associated with clozapine has recently been said to be underestimated (Schulte, 2011). Other reports of neuroleptics-associated myocarditis included fluphenazine, haloperidol, and risperidone (Coulter et al., 2001).

We observed experimentally the development of myocarditis with a number of neuroleptics including amisulpride, haloperidol, levomepromazine, olanzapine, risperidone as well as combinations of levomepromazine and haloperidol or risperidone (Belhani et al., 2006). Indeed, global ventricular hypertrophy was found in rabbits treated with olanzapine and chiefly the combinations levomepromazine-haloperidol and levomepromazinerisperidone; necrosis with amisulpride and haloperidol; endocardial fibrosis with levomepromazine; but no marked lesions with risperidone. Overall, these abnormal findings are similar to those seen in toxic myocarditis induced in previously healthy hearts.

\section{PREVENTION OF OTC PROLONGATION IN PATIENTS TREATED WITH PSYCHOTROPIC DRUGS}

NB: The evaluation of the risk/benefit ratio for drugs that prolong the QT/QTc interval should take into account morbidity/mortality associated with the disease as well as the lack of treatment of the disease.

The prevention of QT interval prolongation is based on a number of parameters, which should be known to reduce the generation of TDPs and sudden death. It is primarily based on ECG recording and the interpretation of results, on blood ion levels, on the torsadogenic potential of the (psychotropic) drug(s) of concern, and on the existence of risk factors.

Risk factors for the prolongation of the QT interval and the generation of TDPs are of extra-cardiac, cardiac, and drug origin. Drug-induced TDPs mainly develop when two or more drugs are combined, which highlights the role of drug interactions. The existence of one or several risk factors requires ECG recording prior to treatment with psychotropic drugs, especially when the intravenous route is to be used (Meyer-Massetti et al., 2010).

\section{RISK FACTORS OF TDP}

Many risk factors have been shown to be involved in the development of TDP, including gender (women), pre-existing cardiovascular diseases (especially bradycardia), electrolytic disturbances, and congenital long QT syndrome (Letsas et al., 2009; Alvarez and Pahissa, 2010). They must be searched for prior to starting treatment with neuroleptics or anti-depressants, and include extra-cardiac and cardiac risk factors.

\section{Age, and hepatic and renal function of patients}

Cardiac accidents tend to be more frequent in elderly patients because of their "physiological" decrease in hepatic and/or renal function due to senescence (Vieweg et al., 2009). Overt hepatic and/or renal failure can also be involved as they reduce the biotransformation and/or elimination of drugs. Adaptation of drug dosage may be needed (Haddad and Anderson, 2002).

\section{Gender}

Testosterone provides some protection to men (Stöllberger et al., 2005; Vieweg et al., 2009). The difference in the susceptibility to TDP across gender appears after puberty only, which suggests that sex hormones may contribute. In male humans, testosterone has been shown to reduce the duration of the action potential and hence of the QTc interval. In contrast, estradiol can potentiate the effects of drugs that prolong the QT interval. Sex hormones have been suggested to alter $\mathrm{Ca}^{2+}$ and/or $\mathrm{K}^{+}$currents, which could also account for differences observed in the action of drugs on the repolarization of cardiac cells (Coker, 2008).

\section{Genetic polymorphism}

Cytochromes P450 (CYP450) are a group of enzymes specialized in the metabolism of drugs that play a pivotal role in biotransformation processes involving xenobiotics (Hasler, 1999; Nelson, 1999). CYP450 isoenzymes are involved in the metabolism of most neuroleptics including clozapine, haloperidol, perphenazine, risperidone, thioridazine, aripiprazole, as well as tricyclic antidepressants and ISRS (Wilkinson, 2005). For instance, more than $25 \%$ of drugs including anti-depressants and neuroleptics are metabolized by CYP2D6. CYP2D6 is characterized by a wide genetic polymorphism (approx. 80 identified alleles) and interethnic variability. Slow metabolizers with a very low metabolic activity account for $5-10 \%$ of the Caucasian population, and ultra-rapid metabolizers from 1 to $10 \%$ of the Caucasian population. They can be affected either by more severe adverse effects or therapeutic inefficacy, depending on whether or not the drug of interest should be metabolized to become active. Intermediate (10-15\%) and good metabolizers (65-80\%) have a fairly similar metabolic activity. Phenotyping and genotyping can be useful tools to identify atrisk patients and lead to a more effective and safer individualized therapy. This is a very important point. Indeed, the activity of clozapine, which is metabolized by CYP2D6, is increased in case of deficiency and in turn the risk of adverse effects induced by clozapine is increased (Jerling et al., 1994; Kang et al., 2000).

\section{CARDIAC RISK FACTORS Bradycardia}

Whatever its origin (physiological or pathological), bradycardia can prolong the QT interval by delaying cellular repolarization in patients treated with neuroleptics (Dhein et al., 2008). There is also a higher risk in patients treated with bradycardia-inducing drugs such as digitalis and in patients with bradycardia of pathological origin, such as hypothyroidism (Micallef et al., 2011). Among ECG recorded in 688 psychiatric patients treated with psychotropic drugs, QTc > 460 ms was observed in 96 patients (14\%; Sadanaga et al., 2004). To elucidate the relationship between heart rate and duration of the QT interval, these authors measured QT and RR intervals by ECG Holter during $24 \mathrm{~h}$ in 97 patients. They showed that for a heart rate of $80 / \mathrm{min}$, the duration of the QT interval was in the range of $400 \mathrm{~ms}$, and for a heart rate of $50 / \mathrm{min}$, the duration exceeded $480 \mathrm{~ms}$. This study stresses the heart rate-dependency of the QT interval duration.

\section{Slowing of supraventricular conduction}

Any slowing and obviously the presence of an auriculoventricular block (AVB) is an important risk factor of TDP (Yiginer et al., 2010). 
Table 5 | Different types of CYP 450, their substrates, and inhibitors (Prior and Baker, 2003).

\begin{tabular}{|c|c|c|}
\hline Types of CYP 450 & $\begin{array}{l}\text { Neuroleptic drugs } \\
\text { substrates of CYP } 450\end{array}$ & Drugs inhibiting CYP 450 \\
\hline CYP 450- 1A2 & Clozapine, haloperidol, olanzapine & Ciprofloxacin, enoxacin, fluvoxamine, cimetidine \\
\hline CYP 450- 3A4 & $\begin{array}{l}\text { Clozapine, haloperidol, pimozide, ziprasidone, } \\
\text { aripiprazole }\end{array}$ & $\begin{array}{l}\text { Fluvoxamine, fluoxetine, ciprofloxacin, itraconazole, ketoconazole, } \\
\text { erythromycin, clarithromycin, indinavir, ritonavir, delavirdine, efavirenz, } \\
\text { methadone, amiodarone, cimetidine, nefazodone, grapefruit juice }\end{array}$ \\
\hline CYP 450- 2D6 & $\begin{array}{l}\text { Clozapine, haloperidol, perphenazine, risperidone, } \\
\text { thioridazine, aripiprazole }\end{array}$ & $\begin{array}{l}\text { Fluoxetine, paroxetine, cimetidine, quinidine, ritonavir, amiodarone, } \\
\text { clomipramine, chlorpheniramine, methadone }\end{array}$ \\
\hline
\end{tabular}

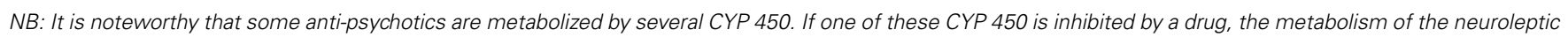

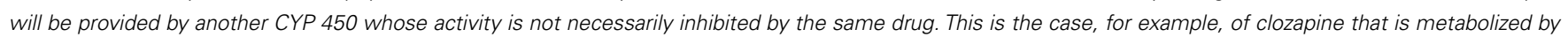
the CYP 450 1A2, 3A4, and 2D6. If the activity of CYP $4501 A 2$ is inhibited by ciprofloxacin, enoxacin, fluvoxamine, and cimetidine, the CYP $4503 A 4$ and 2D6 ensure, at least in part, the metabolism of clozapine.

Table 6 | Drugs that may prolong the QT interval.

\begin{tabular}{ll}
\hline Therapeutic class & Drugs involved \\
\hline Class la antiarrhythmics & Hydroquinidine, disopyramide \\
Class III antiarrhythmics & Amiodarone, sotalol, ibutilide \\
Class IV antiarrhythmics & Bepridil \\
Antibiotics (macrolis) & Erythromycin \\
Synthetic antimalarial agents & Halofantrine \\
Anti leishmania agents and & Pentamidine diisethionate \\
trypanocides & \\
$\mathrm{H}_{1}$ antihistaminics & Mizolastine: this drug slightly lengthens \\
& the QT interval
\end{tabular}

\section{Channelopathies}

The presence of Romano Ward or Timothy syndrome considerably increases the generation of TdP associated with psychotropic drugs that can prolong the QT interval. It is absolutely required to evaluate this risk and adapt treatment.

\section{DRUG-RELATED RISK FACTORS: DRUG INTERACTIONS Pharmacokinetic interactions: enzyme inhibitors}

Such interactions develop in particular when psychotropic drugs are associated with drugs that interact with various CYP450 (Prior and Baker, 2003). Indeed, the combination of a psychotropic drug with another drug that inhibits the enzyme involved in metabolism can induce an increase in plasma levels, and potentially tissue levels with resulting toxicity. The main psychotropic drugs and CYP450 involved in their metabolism and specific enzyme inhibitors are summarized in Table 5 .

\section{Pharmacodynamic interactions}

The use of potentially torsadogenic neuroleptics increases the risk of TDP when associated with another drug that can prolong the QT interval (Cubeddu, 2003; Table 6). Such an association should therefore be avoided or considered only very carefully.

Hypokalemia (Frimas et al., 2008)

Hypokalemia of pathological or drug-induced origin can shift resting potential toward less negative values and thus considerably
Table 7 | Drugs responsible for hypokalemia.

\begin{tabular}{ll}
$\begin{array}{l}\text { Hypokalemia and } \\
\text { mechanisms for its } \\
\text { occurrence }\end{array}$ & Drugs involved \\
\hline $\begin{array}{l}\text { Prokinetic effect } \\
\text { Digestive loss } \\
\text { Urinary loss }\end{array}$ & Cisapride (Prepulsid@) \\
& Laxatives, Kayexalate \\
& Glucocorticoids \\
& Mineralocorticoids \\
& High ceiling diuretics and thiazides \\
& Glycyrrhizinic acid \\
& $\beta$-Lactamines at high doses \\
& Aminosides \\
& Amphotericin B (by acute tubular necrosis) \\
$\beta_{2}$ Mimetics (IV): salbutamol, adrenalin \\
Insulin at high doses (IV) \\
Blood alkalinizing drugs
\end{tabular}

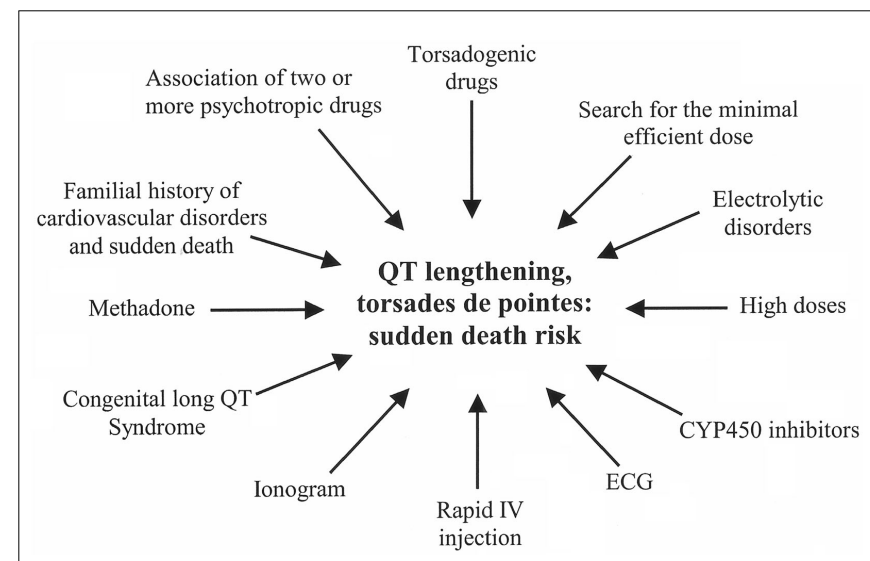

FIGURE 5 | How to handle prescription of a potentially torsadogenic psychotropic in patients at-risk.

increase the risk of TDP. It is therefore recommended to avoid the combination of neuroleptics with hypokalemiant drugs or 
attempts to correct hypokalemia. Hypokalemia can have various origins (Table 7):

\section{CONCLUSION}

The cardiovascular toxicity of psychotropic drugs can display various clinical manifestations including orthostatic hypotension, syncope, myocardial ischemia, myocarditis, cardiac arrhythmias (reentry arrhythmias, torsade de pointes...) among which some may lead to sudden death. These manifestations, in particular

\section{REFERENCES}

Alvarez, P. A., and Pahissa, J. (2010). QT alterations in psychopharmacology: proven candidates and suspects. Curr. Drug Saf. 5, 97-104.

Antzelevitch, C., Brugada, P., Borggrefe, M., Brugada, J., Brugada, R., Corrado, D., Gussak, I., LeMarec, H., Nademanee, K., Perez Riera, A. R., Shimizu, W., Schulze-Bahr, E., Tan, H., and Wilde, A. (2005). Brugada syndrome: report of the second consensus conference: endorsed by the Heart Rhythm Society and the European Heart Rhythm Association. Circulation 111, 659-670.

Barnett, A. H., Millar, H. L., Loze, J. Y., L'Italien, G. J., van Baardewijk, M., and Knapp, M. (2009). UK cost-consequence analysis of aripiprazole in schizophrenia: diabetes and coronary heart disease risk projections (STAR study). Eur. Arch. Psychiatry Clin. Neurosci. 259, 239-247.

Belhani, D., Frassati, D., Mégard, R., Tsibiribi, P., Bui-Xuan, B., Tabib, A., Fanton, L., Malicier, D., Descotes, J., and Timour, Q. (2006). Cardiac lesions induced by neuroleptic drugs in the rabbit. Exp. Toxicol. Pathol. 57, 207-212.

Brown, S. (1997). Excess mortality of schizophrenia. A meta-analysis. $\mathrm{Br}$. J. Psychiatry 171, 502-508.

Brugada, P., Benito, B., Brugada, R., and Brugada, J. (2009). Brugada syndrome: update 2009. Hellenic J. Cardiol. 50, 352-372.

Brugada, P., Brugada, R., Antzelevitch, C., and Brugada, J. (2005). The Brugada syndrome. Arch. Mal. Coeur Vaiss. 98, 115-122.

Coker, S. J. (2008). Drugs for men and women - how important is gender as a risk factor for TdP? Pharmacol. Ther. 119, 186-194.

Coulter, D. M., Bate, A., Meyboom, R. H., Lindquist, M., and Edwards, I. R. (2001). Antipsychotic drugs and heart muscle disorder in international pharmacovigilance: data mining study. BMJ 322, 1207-1209.
Cruchaudet, B., Eicher, J. C., Sgro, C., and Wolf, J. E. (2002). Myocardiopathie réversible induite par les médicaments psychotropes. À propos d'un cas, revue de la littérature. Ann. Cardiol. Angeiol. (Paris) 51, 386-390.

Cubeddu, L. X. (2003). QT prolongation and fatal arrhythmias: a review of clinical implications and effects of drugs. Am. J. Ther. 10, 452-457.

Curtis, L. H., Østbye, T., Sendersky, V., Hutchison, S., Allen LaPointe, N. M., Al-Khatib, S. M., Usdin Yasuda, S., Dans, P. E., Wright, A., Califf, R. M., Woosley, R. L., and Schulman, K. A. (2003). Prescription of QT-prolonging drugs in a cohort of about 5 million outpatients. Am. J. Med. 114, 135-41.

Darbar, D., Yang, T., Churchwell, K., Wilde, A. A., and Roden, D. M. (2005). Unmasking of brugada syndrome by lithium. Circulation 112, 1527-1531.

Dhein, S., Perlitz, F., and Mohr, F. W. (2008). An in vitro model for assessment of drug-induced torsade de pointes arrhythmia: effects of haloperidol and dofetilide on potential duration, repolarization inhomogeneities, and torsade de pointes arrhythmia. Naunyn Schmiedebergs Arch. Pharmacol. 378, 631-644.

Drago, A., De Ponti, F., Boriani, G., De Ronchi, D., and Serretti, A. (2008). Strategy for a genetic assessment of antipsychotic and antidepressantrelated proarrhythmia. Curr. Med. Chem. 15, 2472-517.

Dubnov, G., Fogelman, R., and Merlob, P. (2005). Prolonged QT interval in an infant of a fluoxetine treated mother. Arch. Dis. Child. 90, 972-973.

Frassati, D., Tabib, A., Lachaux, B., Giloux, N., Daléry, J., Vittori, F., Charvet, D., Barel, C., Bui-Xuan, B., Mégard, R., Jenoudet, L. P., Descotes, J., Vial, T., and Timour, Q. (2004). Hidden cardiac lesions and psychotropic drugs as a possible cause of sudden death in psychiatric patients: a report of 14 cases and review of

sudden death, are more common in patients with congenital or acquired cardiac risk factors, including hypertrophic and/or dilated cardiopathies, ischemic cardiopathies, combination of prescribed drugs that prolong QRS complexes or QT intervals, or drugs that can induce hypokalemia or bradycardia.

Particular precautionary measures should be taken including blood ionic balance, ECG recording, and even cardiac echography, to reduce the risk of cardiac adverse events that may be life-threatening (Figure 5).

the literature. Can. J. Psychiatry 49, 100-105.

Frimas, V., Roberge, C., Perroux, D., and Dauvillier, J. M. (2008). Cardiological monitoring of antipsychotic-treated patients: evaluation and evolution of a hospital protocol. Encephale 34, 467-476.

Haddad, P. M., and Anderson, I. M. (2002). Antipsychotic-related QTc prolongation, torsade de pointes and sudden death. Drugs 62, 1649-1671.

Hansen, V., Arnesen, E., and Jacobsen, B. K. (1997). Total mortality in people admitted to a psychiatric hospital. Br. J. Psychiatry 170, 186-190.

Harris, E. C., and Barraclough, B. (1998). Excess mortality of mental disorder. Br. J. Psychiatry 173, 11-53.

Hasler, J. A. (1999). Pharmacogenetics of cytochromes P450. Mol. Aspects Med. 20, 25-137.

Jerling, M., Lindström, L., Bondesson, U., and Bertilsson, L. (1994). Fluvoxamine inhibition and carbamazepine induction of the metabolism of clozapine: evidence from a therapeutic drug monitoring service. Ther. Drug. Monit. 16, 368-374.

Jin, H., Folsom, D., Sasaki, A., Mudaliar, S., Henry, R., Torres, M., Golshan, S., Glorioso, D. K., and Jeste, D. (2011). Increased Framingham 10year risk of coronary heart disease in middle-aged and older patients with psychotic symptoms. Schizophr. Res. 125, 295-299.

Kang, U. G., Kwon, J. S., Ahn, Y. M., Chung, S. J., Ha, J. H., Koo, Y. J., and Kim, Y. S. (2000). Electrocardiographic abnormalities in patients treated with clozapine. J. Clin. Psychiatry 61, 441-446.

Kilian, J. G., Kerr, K., Lawrence, C., and Celermajer, D. S. (1999). Myocarditis and cardiomyopathy associated with clozapine. Lancet 354, 1841-1845.

Killeen, M. J. (2009). Antipsychoticinduced sudden cardiac death: examination of an atypical reaction. Expert Opin. Drug Saf. 8, 249-252.

Kitayama, H., Kiuchi, K., Nejima, J., Katoh, T., Takano, T., and Hayakawa, H. (1999). Long-term treatment with antipsychotic drugs in conventional doses prolonged QTc dispersion, but did not increase ventricular tachyarrhythmias in patients with schizophrenia in the absence of cardiac disease. Eur. J. Clin. Pharmacol. 55, 259-262.

Langendijk, P. N., and Wilde, A. A (2006). Medication for ADHD and the risk of cardiovascular mortality. Ned. Tijdschr. Geneeskd. 150, 1713-1714.

Lee, H. A., Kim, K. S., Park, S. J. and Kim, E. J. (2009). Cellular mechanism of the QT prolongation induced by sulpiride. Int. J. Toxicol. 28, 207-212.

Leonard, H. L., Meyer, M. C., Swedo, S. E., Richter, D., Hamburger, S. D., Allen, A. J., Rapoport, J. L., and Tucker, E. (1995). Electrocardiographic changes during desipramine and clomipramine treatment in children and adolescents. J. Am. Acad. Child Adolesc. Psychiatry 34, 1460-1468.

Letsas, K. P., Efremidis, M., Kounas, S. P., Pappas, L. K., Gavrielatos, G., Alexanian, I. P., Dimopoulos, N. P., Filippatos, G. S., Sideris, A., and Kardaras, F. (2009). Clinical characteristics of patients with drug-induced QT interval prolongation and torsade de pointes: identification of risk factors. Clin. Res. Cardiol. 98, 208-212.

Levy, D., Garrison, R. J., Savage, D. D., Kannel, W. B., and Castelli, W. P. (1990). Framingham Heart Study. N. Engl. J. Med. 322, 1561-6.

Lin, C. H., Chen, M. C., Wang, S. Y., and Lin, C. Y. (2004). Predictive factors for QTc prolongation in schizophrenic patients taking antipsychotics. J. Formos. Med. Assoc. 103, 437-41.

Lo Vecchio, F., Hamilton, R. J., and Hoffman, R. J. (1996). Risperidone overdose. Am. J. Emerg. Med. 14, 95-6.

Mehtonen, O. P., Aranko, K., Mälkonen, L., and Vapaatalo, H. (1991). A survey of sudden death associated with the use of antipsychotic or antidepressant drugs: 49 cases in Finland. Acta Psychiatr. Scand. 84, 58-64. 
Meyer-Massetti, C., Cheng, C. M., Sharpe, B. A., Meier, C. R., and Guglielmo, B. J. (2010). The FDA extended warning for intravenous haloperidol and torsades de pointes: how should institutions respond? J. Hosp. Med. 5, 8-16.

Micallef, T., Gruppetta, M., Cassar, A., and Fava, S. (2011). Takotsubo Cardiomyopathy in a patient with severe hypothyroidism: a case report. J. Cardiovasc. Med. (Hagerstown). 12, 824-7.

Mladosievicova, B., Hulin, I., Pogady, J., Martisova, D., Petrasova, H., and Hubka, P. (1996). Signal-averaged ECG in patients with antidepressant therapy. Int. J. Cardiol. 54, 27-31.

Narang, P., El-Refai, M., Parlapalli, R., Danilov, L., Manda, S., Kaur, G., and Lippmann, S. (2010). Antipsychotic drugs: sudden cardiac death among elderly patients. Psychiatry (Edgmont) 7, 25-29.

Navedo, M. F., Cheng, E. P., Yuan, C., Votaw, S., Molkentin, J. D., Scott, J. D., and Santana, L. F. (2010). Increased coupled gating of L-type $\mathrm{Ca}^{2+}$ channels during hypertension and Timothy syndrome. Circ. Res. 106, 748-756.

Nelson, D. R. (1999). Cytochrome P450 and the individuality of species. Arch. Biochem. Biophys. 369, 1-10.

Newman, S. C., and Bland, R. C. (1991). Mortality in a cohort of patients with schizophrenia: a record linkage study. Can. J. Psychiatry 36, 239-245.

Olanzapine: New Preparation. Keep an eye on this neuroleptic. (1999). Prescrire. Int. 8, 135-138.

Pacher, P., and Kecskeméti, V. (2004). Cardiovascular effects of selective serotonin reuptake inhibitor antidepressants. Orv. Hetil. 145, 425-431.

Pacher, P., and Kecskemeti, V. (2004). Cardiovascular side effects of new antidepressants and antipsychotics: new drugs, old concerns? Curr. Pharm. Des. 10, 2463-2475.

Prior, T. I., and Baker, G. B. (2003). Interactions between the cytochrome P450 system and the second-generation antipsychotics. J. Psychiatry Neurosci. 28, 99-112.

Raedler, T. J. (2010). Cardiovascular aspects of antipsychotics.
Curr. Opin. Psychiatry 23, 574-581.

Rajamani, S., Eckhardt, L. L., Valdivia, C. R., Klemens, C. A., Gillman, B. M., Anderson, C. L., Holzem, K. M., Delisle, B. P., Anson, B. D., Makielski, J. C., and January, C. T. (2006). Drug-induced long QT syndrome: hERG $\mathrm{K}+$ channel block and disruption of protein trafficking by fluoxetine and norfluoxetine. $B r . J$. Pharmacol. 149, 481-489.

Raviña, T., Gutierrez, J., and Raviña, P. (2007a). Acquired long QT syndrome: long-term electrocardiographic (Holter) recording of torsades de pointes ending in asystole: II. Int. J. Cardiol. 116, 272-275.

Raviña, T., Raviña, P., and Gutierrez, J. (2007b). Acquired long QT syndrome: risperidone-facilitated triggered activity and torsades de pointes during complete $\mathrm{AV}$ block. Int. J. Cardiol. 116, 416-420.

Rouleau, F., Asfar, P., Boulet, S., Dube, L., Dupuis, J. M., Alquier, P., and Victor, J. (2001). Transient ST segment elevation in right precordial leads induced by psychotropic drugs: relationship to the Brugada syndrome. $J$. Cardiovasc. Electrophysiol. 12, 61-65.

Ruschena, D., Mullen, P. E., Burgess, P., Cordner, S. M., Barry-Walsh, J., Drummer, O. H., Palmer, S., Browne, C., and Wallace, C. (1998). Sudden death in psychiatric patients. Br. J. Psychiatry 172, 331-336.

Sadanaga, T., Sadanaga, F., Yao, H., and Fujishima, M. (2004). Abnormal QT prolongation and psychotropic drug therapy in psychiatric patients: significance of bradycardia-dependent QT prolongation. J. Electrocardiol. $37,267-273$.

Schulte, P. F. (2011). Reaction on myocarditis and cardiomyopathy underestimated complications resulting from clozapine therapy. Tijdschr. Psychiatr. 53, 193-194.

Sicouri, S., and Antzelevitch, C. (2008). Sudden cardiac death secondary to antidepressant and antipsychotic drugs. Expert Opin. Drug Saf. 7, 181-194.

Stirnimann, G., Petitprez, S., Abriel, H., and Schwick, N. G. (2010). Brugada syndrome ECG provoked by the selective serotonin reuptake inhibitor fluvoxamine. Europace 12, 282-283.

Stöllberger, C., Huber, J. O., and Finsterer, J. (2005). Antipsychotic drugs and QT prolongation. Int. Clin. Psychopharmacol. 20, 243-251.

Suvisaari, J., Perälä, J., Saarni, S. I., Kattainen, A., Lönnqvist, J., and Reunanen, A. (2010). Coronary heart disease and cardiac conduction abnormalities in persons with psychotic disorders in a general population. Psychiatry Res. 175, 126-132.

Talati, S. N., Aslam, A. F., and Vasavada, B. (2009). Sinus node dysfunction in association with chronic lithium therapy: a case report and review of literature. Am. J. Ther. 16 274-278.

Thorogood, M., Cowen, P., Mann, J., Murphy, M., and Vessey, M. (1992). Fatal myocardial infarction and use of psychotropic drugs in young women. Lancet 340, 1067-1068.

van Noord, C., Straus, S. M., Sturkenboom, M. C., Hofman, A., Aarnoudse, A. J., Bagnardi, V. Kors, J. A., Newton-Cheh, C., Witteman, J. C., and Stricker, B. H. (2009). Psychotropic drugs associated with corrected QT interval prolongation. J. Clin. Psychopharmacol. 29, 9-15.

Vieweg, W. V., Wood, M. A., Fernandez, A., Beatty-Brooks, M., Hasnain, M. and Pandurangi, A. K. (2009). Proarrhythmic risk with antipsychotic and antidepressant drugs: implications in the elderly. Drugs Aging 26, 997-1012.

Volkov, V. P. (2009). Phenothiazineinduced dilatation cardiomyopathy: selected aspects of clinical course and morphology. Klin Med (Mosk.) 87, 13-6.

Waring, W. S. (2007). Delayed cardiotoxicity in chronic lithium poisoning: discrepancy between serum lithium concentrations and clinical status. Basic Clin. Pharmacol. Toxicol. 100, 353-355.

Warner, J. P., Barnes, T. R., and Henry, J. A. (1996). Electrocardiographic changes in patients receiving neuroleptic medication. Acta Psychiatr. Scand. 93, 311-313.

Wilens, T. E., Stern, T. A., and O'Gara, P. T. (1990). Adverse cardiac effects of combined neuroleptic ingestion and tricyclic antidepressant overdose. J. Clin. Psychopharmacol. 10, 51-54.

Wilkinson, G. R. (2005). Drug metabolism and variability among patients in drug response. N. Engl. J. Med. 352, 2211-21.

Yap, Y. G., Behr, E. R., and Camm, A. J. (2009). Drug-induced Brugada syndrome. Europace 11, 989-994.

Yiginer, O., Kilicaslan, F., Aparci, M., Isilak, Z., Uz, O., Bayrak, F., Eroglu, E., Uzun, M., Kardesoglu, E., Kirilmaz, A., and Cebeci, B. S. (2010). Advanced age, female gender and delay in pacemaker implantation may cause $\mathrm{TdP}$ in patients with complete atrioventricular block. Indian Pacing Electrophysiol. J. 10, 454-463.

Yim, K. M., Ng, H. W., Chan, C. K., Yip, G., and Lau, F. L. (2008). Sibutramine-induced acute myocardial infarction in a young lady. Clin. Toxicol. 46, 877-879.

Conflict of Interest Statement: The authors declare that the research was conducted in the absence of any commercial or financial relationships that could be construed as a potential conflict of interest.

Received: 09 March 2012; paper pending published: 29 March 2012; accepted: 10 April 2012; published online: 10 May 2012.

Citation: Timour Q, Frassati D, Descotes $J$, Chevalier P, Christé G and Chahine $M$ (2012) Sudden death of cardiac origin and psychotropic drugs. Front. Pharmacol. 3:76. doi: 10.3389/fphar.2012.00076 This article was submitted to Frontiers in Pharmacology of Ion Channels and Channelopathies, a specialty of Frontiers in Pharmacology.

Copyright (c) 2012 Timour, Frassati, Descotes, Chevalier, Christé and Chahine. This is an open-access article distributed under the terms of the Creative Commons Attribution Non Commercial License, which permits noncommercial use, distribution, and reproduction in other forums, provided the original authors and source are credited. 